\title{
SECOND ATTACKS OF ACUTE POLIOMYELITIS, AND THE MINIMAL DURATION OF IMMUNITY
}

\author{
BY \\ G. F. STILL, M.D., L.L.D., F.R.C.P. \\ Consulting Physician, Hospital for Sick Children, Great Ormond Street ; \\ Professor, Diseases of Children, King's College, London.
}

Acute anterior poliomyelitis, like some other diseases due to a specific infection, seems to confer immunity for a time. At present there is but little evidence to show how long this immunity lasts. There is proof, in the occurrence of second attacks, that it is not always permanent.

The late Dr. F. E. Batten ${ }^{1}$, in his Lumleian lectures on acute poliomyelitis (1916), said that no instance of a second attack had come under his observation. Referring to three cases reported by Oulmont and Baudouin, Eshner ${ }^{3}$, and $\mathrm{Sanz}^{4}$, he said ' not one of these cases appears to me to be convincing or to bear critical investigation.' I had independently come to the same conclusion with regard to the case reported by Oulmont and Baudouin; and Eshner himself regarded the nature of the second attack in his own case as doubtful; the third case, by Sanz, I have included in a series of collected cases as one of reasonable probability.

After exclusion of the two doubtful cases I have been able to find only eight recorded cases in which there seemed to be a clear history of a second attack of acute poliomyelitis (see Table).

To this list may be added the following case.

Dorothy V., aged $7 \frac{1}{2}$ years, was admitted to King's College Hospital on October 14th, 1929. At the age of $1 \frac{3}{4}$ years she had an attack of acute poliomyelitis which left her with a wasted and paralysed left leg, so that she was obliged to wear an iron support for walking and is still crippled.

At $7 \frac{1}{2}$ years old, on September 30th, 1929, she stumbled in walking and fell, but did not hurt herself badly. On the night of October lst, she had pain in the back of the neck, and was feverish and sweated. The pain persisted, so that she was kept in bed for three days. On October 5th she went out in the garden and fell down, and found she could not pick herself up. Her walking was as it had been before, but she now found that if she sat on the floor she could not get herself up into the standing position. The reason was obvious when she was admitted to hospital, for the muscles of the right shoulder were found to be paralysed. She could not abduct the arm, nor raise it so as to put her hand on her head. Flabbiness and then wasting appeared, especially in the right supra-spinatus and deltoid muscles, and five weeks after admission there was reaction of degeneration in the deltoid, and the reaction in the infra-spinatus was diminished both to faradism and galvanism. Ten weeks after admission there was visible wasting of the right infra-spinatus and supra-spinatus, and especially of the deltoid muscle : there was considerable recovery of movement, the child could now put her right hand on the top of her head with some special effort. There was no affection of the rest of the limb.

So far as can be judged from clinical evidence this case appears to be a clear instance of a second attack of poliomyelitis after an interval of $5 \frac{3}{4}$ years. 
It adds therefore to the evidence already accumulated that an attack of acute poliomyelitis does not necessarily confer permanent immunity.

This is no proof that such an attack does not confer temporary immunity; nor indeed that it does not sometimes, or even usually, confer permanent immunity. The history of other infectious diseases, even those which experience has shewn to be most highly protective, makes it unlikely that the immunity conferred by this disease should always be permanent. Second attacks have been known even in variola and varicella which are very highly protective, and whooping-cough, though it usually gives permanent immunity, does not always do so. Indeed it may be doubted whether any form of infection necessarily establishes permanent immunity.

TABLE.

REPORTED CASES OF SECOND ATtaCkS OF ACUTE POLIOMYelitis.

\begin{tabular}{|c|c|c|c|c|c|c|}
\hline $\begin{array}{l}\text { Case } \\
\text { No. }\end{array}$ & Author & & Sex & Ages of attacks & $\begin{array}{l}\text { Interval } \\
\text { of } \\
\text { attacks }\end{array}$ & $\begin{array}{l}\text { Parts } \\
\text { affected }\end{array}$ \\
\hline 1 & Caudouin ${ }^{7}$ & . & $\mathbf{M}$ & 17 mo., 16 yr. & $14 \mathrm{yr}$. & $\begin{array}{l}\text { 1. L. leg. } \\
\text { 2. R. leg. }\end{array}$ \\
\hline 2 & Ballet \& Dutil ${ }^{8}$ & . & $\mathbf{F}$ & $3 \mathrm{yr} ., 12 \mathrm{yr} ., 14 \mathrm{yr}$. & $\begin{array}{l}9 \mathrm{yr} . \\
2 \mathrm{gr} .\end{array}$ & $\begin{array}{l}\text { 1. L. leg. } \\
\text { 2. Both arms. } \\
\text { 3. Both legs. }\end{array}$ \\
\hline 3 & Eckert $^{9} \quad \ldots \quad$. & . & & & $5 \mathrm{yr}$. & $\begin{array}{l}\text { 1. L. leg. } \\
\text { 2. R. leg. }\end{array}$ \\
\hline 4 & Lucas \& Osgood ${ }^{10}$ & & M & 2 yr., 5 yr. & $2 \mathrm{yr}$. & $\begin{array}{l}\text { 1. Both feet and R. leg. } \\
\text { 2. R. arm and both legs weak. }\end{array}$ \\
\hline 5 & $\begin{array}{lll}\operatorname{Sanz}^{4} & \ldots & \text {. }\end{array}$ & .. & $\mathbf{F}$ & 1 yr., 15 yr. & $14 \mathrm{yr}$. & $\begin{array}{l}\text { 1. L. leg. } \\
\text { 2. R. leg. }\end{array}$ \\
\hline 6 & Taylor $^{11} \ldots$. & $\cdots$ & $\mathbf{M}$ & 3 yr., 6 yr. & 3 yr. & $\begin{array}{l}\text { 1. R. leg. } \\
\text { 2. L. leg. }\end{array}$ \\
\hline 7 & Francis \& Moncrief & $\mathrm{ff}^{12}$ & $\mathbf{F}$ & 3 yr., 18 yr. & $15 \mathrm{yr}$. & $\begin{array}{l}\text { 1. R. arm. } \\
\text { 2. Both legs. }\end{array}$ \\
\hline 8 & Peremans ${ }^{13}$ & .. & $\mathbf{F}$ & $2 \frac{3}{4} \mathrm{yr} ., 4 \frac{3}{4} \mathrm{yr}$ & $2 \mathrm{yr}$ & $\begin{array}{l}\text { 1. L. leg. } \\
\text { 2. One arm. }\end{array}$ \\
\hline 9 & Author .. . & . & $\mathbf{F}$ & $1 \frac{3}{4} \mathrm{yr} ., 7 \frac{1}{2} \mathrm{yr}$ & $5 \frac{3}{4} \mathrm{yr}$ & $\begin{array}{l}\text { 1. L. leg. } \\
\text { 2. R. shoulder. }\end{array}$ \\
\hline
\end{tabular}

Minimal duration of immunity.-If the minimal duration of immunity from a fresh infection with the virus of poliomyelitis could be determined, it would afford some guidance, during an epidemic of the disease, in the care of those children who had already had an attack of it.

In seeking to arrive at a solution of this question of duration of immunity, it is necessary to distinguish sharply between recrudescence and re-infection. A considerable number of cases have been recorded in which recurrence of symp- 
toms and extension of paralysis have occurred several days or weeks after the first onset. The interval has varied from one week up to twelve weeks. Probably no one, in view of the known duration of the infection in the monkey and in the child, would suggest that these were anything but exacerbations or extensions of the original infection.

There is experimental evidence that the infection may be harboured by a child for at least four months. In Case 4 in the accompanying Table, Lucas and Osgood produced the disease in a monkey by inoculation with the nasal secretion from the child four months after his second attack. This case offers no evidence as to longer persistence of the infection, but it is stated on the authority of the Royal Medical Institute of Sweden ${ }^{5}$ that in the epidemic which occurred in 1911 in that country, infection was proved by inoculation experiments to persist in the mouth and intestine of persons affected for periods extending up to seven months.

This, however, does not prove that the child is liable to a fresh attack of the disease during this period, for he may be immune though still a carrier ; indeed the few available observations collected here seem to show that within the period during which he may still be carrying infection the child acquires, either at once or after one or more recrudescences, an immunity which has a certain minimal duration.

The minimal duration of this immunity could be determined with some degree of accuracy if large numbers of observations of second attacks were available, but the total number at present is so small that it affords only sufficient grounds for a conclusion which may have to be revised in the light of further experience.

Apart from the many cases recorded in which symptoms of acute poliomyelitis recurred or recrudesced within three months after the first onset, there is, with one very doubtful exception*, no case on record so far as I have been able to ascertain of recurrence of symptoms after an interval of three months until an interval of two years is reached : in other words there is apparently a silent period of two years between the time when recrudescence ceases to occur and the time when liability to a fresh attack begins to appear. In four out of the nine cases collected here the interval between any two attacks was 2 to $2 \frac{1}{2}$ years, and in another it was 3 years : the others were all after longer intervals. In one of this series (Case 2) there were three separate attacks of definite acute poliomyelitis, and the intervals between them were 9 years and 2 years. Another (Case 8) was thought to have had an abortive attack consisting only of headache, convulsion and stiffness of the neck, twelve weeks before the first paralytic attack, but the nature of the first illness is so inconclusive that it can hardly be accepted in the absence of other evidence as an attack of acute poliomyelitis : it was followed 12 weeks later by a definite attack of acute poliomyelitis, and then, after an interval of two years, by another attack of poliomyelitis.

*A boy aged 5 years had transient loss of power in both legs for two days only, after which he was quite well until 19 months later when he had an attack of paralysis in the right leg which was left permanently weak (Sheppard ${ }^{6}$ ). The nature of the earlier attack here is obviously very uncertain. 


\section{Conclusions.}

It would seem that there are two groups of recurrence of poliomyelitis, chronologically distinct: those occurring within three months after the first onset, and those occurring after an interval of two years or more.

This silent period, the interval between the two groups, suggests that either as a result of the initial infection or of recrudescence of the infection within the first few weeks, an immunity is established which has a minimal duration of about two years.

\section{REFERENCES.}

1. Batten, F. E., Lancet, Lond., 1916, i, 809.

2. Oulmont, E. and Baudouin, A., Rev. neurolog., Paris, 1911, xxi, 333 ; Rer. Neur. \&. Psych., Edin., 1911, ix, 314.

3. Eshner, A. A., Med. Rec., N.Y., 1910, LXXVIII, 526.

4. Sanz, F., Siglo medico, Madrid, 1915, LXII, 530 ; Rev. Neur. \& Psych., Edin., 1915, XIII, 544.

5. Epidem. of Poliomyelitis in N.Y. City in 1916, 98.

6. Sheppard, -., Inf. paralysis in Massachusetts in 1910, 134.

7. Caudouin, -., Thèse de Paris, Paris, 1879.

8. Ballet, G., \& Dutil, A., Rev. de med., Paris, 1884 IV 18.

9. Eckert, -., Deutsche med. Wchnschr., Leipsig, 1911, XXXVII, i, 113.

10. Lucas, W. P., \& Osgood, R. B., J. Am. Med. Ass., Chic., 1913, LX, 1611.

11. Taylor, E. W., J. Nert. \& Ment. Dis., N.Y., 1916, XLIV, 207.

12. Francis, F. D., \& Moncrieff, W. F., Ibid., 1919, XLIX, 273.

13 Peremans, G., Le Scalpel, Brux., 1923, LXXVI, 1319. 